UNDERGRADUATE RESEARCH IN NATURAL AND CLINICAL SCIENCE AND TECHNOLOGY (URNCST) JOURNAL Read more URNCST Journal articles and submit your own today at: https://www.urncst.com

\title{
Using Prime Editing and Mesenchymal Stem Cell-Derived Exosomes to Treat Cystic Fibrosis: A Research Protocol
}

Erica Akene, High School Student [1], Anastasija Petrovic, High School Student [2], Jessica Song, High School Student [3]*

[1] Pacific Academy, Surrey, British Columbia, Canada V4N 1Z4

[2] New Westminster Secondary School, New Westminster, British Columbia, Canada V3L 3C8

[3] University Hill Secondary School, Vancouver, British Columbia, Canada V6S 0C6

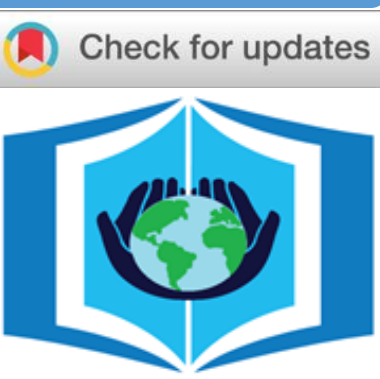

URNCST Journal

"Research in Earnest"

*Corresponding Author: jessicasong1002@gmail.com

\begin{abstract}
Introduction: Cystic Fibrosis $(\mathrm{CF})$ is a progressive genetic disease that causes the production of thick mucus in the lungs. A mutation in the cystic fibrosis transmembrane conductance regulator (CFTR) gene leads to a malfunction of the CFTR protein. Current therapies for cystic fibrosis treat the symptoms rather but not the disease source. This study proposes using prime editing in combination with mesenchymal stem cell-derived exosomes (MSCEs) as an alternative treatment for CF. This treatment could potentially (1) correct the CFTR mutation in lung epithelial cells, and (2) regenerate tissue function after damage caused by cystic fibrosis in the lungs.

Methods: The MSCEs are obtained from adipose tissue through differential centrifugation and ultracentrifugation. They will then be surface engineered with a low molecular weight polyethylene glycol to help better penetrate the mucus layer and after incubated with the prime editor and liposomes to create the hybrid liposome MSCEs and encapsulate the prime editor. Both in vivo and in vitro experiments with mice models and human lung organoids will be used to test the MSCEs and prime editor. After administration, efficiency of the treatment will be measured through the recombinant protein, FVII (rFVII) and microscopy.

Results: The MSCEs will be delivered through nebulization to reach the lung epithelial cells to correct the mutation, leading to the proper expression of the protein in the lungs. The MSCEs will further regenerate damage already caused by the disease.

Discussion: If the treatment is effective, we expect to see the production of thinner mucus in the lungs and an increased ability to breathe over time due to the MSCEs.

Conclusion: Currently, there is no cure for CF and the lifespan of CF patients is around 44 years. MSCEs and prime editing could be a safe and viable option for treating $\mathrm{CF}$.
\end{abstract}

Keywords: cystic fibrosis; mesenchymal stem cell-derived exosomes; prime editing; regenerative medicine; gene therapy

\section{Introduction}

Cystic fibrosis (CF) is an autosomal recessive and single-gene disease that affects over 70,000 people worldwide [1]. CF affects multiple organs, including the lungs. Common symptoms include a buildup of thick mucus, shortness of breath, and frequent lung infections [2]. A mutation in the cystic fibrosis transmembrane regulator (CFTR) gene causes the CFTR protein to become dysfunctional. The mutation inhibits the regulation of chloride ions and water in and out of the epithelia [3, 4]. There are over 1,700 known mutations of the CFTR gene [4], but the F508del mutation that codes for phenylalanine is the most common, accounting for about $70 \%$ of all mutations $[5,6]$.

There have been recent breakthroughs in smallmolecule drugs to treat cystic fibrosis. One of the most promising CF treatments identified is CFTR modulators. Popular CFTR modulators include ivacaftor, lumacaftor, and tezacaftor [7]. These treatments benefit about $45 \%$ of $\mathrm{CF}$ patients and have improved lung function and sweat chloride (a result of defective chloride channels elevated in individuals with CF). These drugs can target specific defects in the CFTR protein to improve their function. CFTR modulators can increase the amount of time the CFTR channel spends in an open position, improve CFTR trafficking or transport to the cell surface and increase CFTR protein production [8]. Although promising, these drugs have several limitations as they do not fully restore chloride flow and only lessen CF symptoms [9]. The CFTR modulators treat specific mutations, which leaves out $30 \%$ of patients [10]. Additionally, $49.3 \%$ of adults in a recent study reported adverse reactions to the drugs, while $22 \%$ of 
UNDERGRADUATE RESEARCH IN NATURAL AND CLINICAL SCIENCE AND TECHNOLOGY (URNCST) JOURNAL Read more URNCST Journal articles and submit your own today at: https://www.urncst.com

patients in the pediatric group showed adverse reactions to the CFTR modulators [10]. Finally, the modulators are expensive, costing over 300,000 USD annually [11], and must be taken every 12 hours as they only work as long as the medication is in the system [12].

A novel therapy for curing cystic fibrosis is the use of gene therapy, specifically CRISPR-Cas9. CRISPR is seen as the gold standard for genome editing and is versatile and highly efficient [13]. However, CRISPR has its disadvantages. CRISPR can make edits in the genome through double-strand breaks (DSBs), where the Cas9 protein breaks both strands of DNA. There are two ways that CRISPR can repair the DSB and fix the mutation; (1) using non-homologous end joining and (2) homologydirected repair. Non-homologous end joining (NHEJ) leverages the cell's natural DNA repair system to patch the damage and make edits. This technique, however, is inaccurate and error-prone, as the repair system will make random insertions and deletions, possibly causing more mutations in the cells. Homology-directed repair (HDR) is the most used and accurate pathway for CRISPR edits. HDR uses homologous chromosomal DNA to serve as a template for the damaged DNA and is a more error-free repair than NHEJ [14]. Even so, HDR is not perfect because of its low efficacy rate. Furthermore, CRISPR has a frequency for off-target effects (OTEs) of $\geq 50 \%$. Other disadvantages of CRISPR include DSBs induced by CRISPR often activate p53 in response to toxic DSBs [14], leading to cell apoptosis instead of the intended gene edit $[11,15]$.

The disadvantages of these therapies are why we propose prime editing and mesenchymal stem cell-derived exosomes. This solution uses permanent gene editing and regenerative medicine to correct the CFTR mutation in lung epithelial cells and regenerate damage from the disease in the lungs. Prime editing is a 'search and replace' geneediting tool that has a catalytically impaired Cas9 endonuclease and a prime editing guide RNA (pegRNA). Prime editors (PEs) use a reverse transcriptase (RT) fused to an RNA-programmable nickase and a pegRNA that specifies the target site and copies genetic information from the pegRNA to the target locus. The pegRNA has both the guide template and the repair template so that the Cas9 endonuclease is able to find the specific section of the DNA and know what base pairs to replace the mutation with. Unlike CRISPR-Cas9, prime editing does not require DSBs or exogenous donor DNA to edit the genome, has far fewer byproducts, and has higher or similar efficiency to Cas9 mediated HDR [16].

Mesenchymal stem cell-derived exosomes (MSCEs) are spherical, nanosized extracellular vesicles ranging from 40-100 $\mathrm{nm}$ in diameter. They are derived from mesenchymal stem cells (MSCs) [17]. MSCs can be harvested from bone marrow, adipose tissue, umbilical cord, placenta and Wharton's Jelly [18]. However, we propose using MSCs derived from adipose tissue as it can be acquired using minimally invasive techniques and has a high stem cell yield [19]. Exosomes and other extracellular vesicles play an important role in intracellular communication, immune responses, homeostasis maintenance, inflammation, angiogenesis, and in the case of MSCEs can have regenerative properties [20]. MSCEs can interact with cells in three ways by (1) entering cells via endocytic uptake, (2) direct fusion of vesicles to the cell membrane, and (3) transmitting their contents through adhesion to the cell surface via lipid-ligand receptors [20]. Compared to traditional delivery mechanisms, MSCEs possess the unique capabilities to increase cell proliferation and angiogenesis and decrease apoptosis, oxidative stress, and fibrosis in the cells. MSCEs can not directly form tumours, can be engineered to target specific cells, and are biodegradable and immunocompatible [21]. In this protocol, we aim to apply prime editing and MSCEs to treat cystic fibrosis (Figure 1).

\section{Methods}

Harvesting and Isolating the MSCs

Human adipose tissue-derived mesenchymal stem cells can be obtained from a subcutaneous liposuction procedure from the trunk or the extremities [22] to collect the lipoaspirate. After the lipoaspirate is collected, the MSCs will be isolated through enzymatic digestion and differential centrifugation [23]. The MSC isolation protocol described was first proposed by Zuk et al. [24]; to separate the stromal vascular fraction (SVF) from the lipoaspirate. The SVF contains a heterogeneous population of cell types, including MSCs. The lipoaspirate is washed with equal volumes of phosphate-buffered saline (PBS) then digested at $37^{\circ} \mathrm{C}$ for 30 minutes with $0.075 \%$ collagenase. Enzyme activity is then neutralized with Dulbecco's modified Eagle's medium (DMEM), which contains 10\% FBS and then centrifuged for 10 minutes at $1200 \mathrm{~g}$ to obtain the high-density SVF pellet. The SVF pellet is then suspended in $\mathrm{NH}_{4} \mathrm{Cl}$ and incubated at room temperature for 10 minutes to lyse contaminating red blood cells. The SVF is then filtered through a $100-\mu \mathrm{m}$ nylon mesh to remove undigested tissue fragments. It is then incubated overnight at $37^{\circ} \mathrm{C} / 5 \%$ $\mathrm{CO} 2$ in the control medium (DMEM, 10\% FBS, $1 \%$ antibiotic/antimycotic solution). Following incubation, the result is a processed lipoaspirate that contains the isolated MSCs.

Isolating and Surface Engineering the MSCEs

After the MSCs have been isolated, differential centrifugation is used to isolate the exosomes. First, cellular debris and large particles are separated from the matrix through two to three centrifugation steps of ten minutes each at $500 \times \mathrm{g}$. Then a $0.22 \mu \mathrm{m}$ filtration and another round of ultracentrifugation for 30 minutes further purify the matrix, removing large extracellular vesicles and apoptotic bodies. Finally, the exosomes are retrieved by two more rounds of ultracentrifugation at approximately 
UNDERGRADUATE RESEARCH IN NATURAL AND CLINICAL SCIENCE AND TECHNOLOGY (URNCST) JOURNAL Read more URNCST Journal articles and submit your own today at: $\underline{\text { https://www.urncst.com }}$

$100,000-120,000 \times \mathrm{g}$ for $60-120$ minutes; and subsequent washing in a PBS $[25,26]$.

Once the MSCEs have been isolated from the parent cells, they will be surface engineered exogenously with polyethylene glycol (PEG) to help the MSCEs penetrate the mucus layer more effectively. A protocol described by Kooijmans et al., [33] uses a phospholipid post-insertion method to decorate EV membranes with 1,2-dimyristoylsn-glycero-3-phosphoethanolamine polyethylene glycol (DMPE-PEG). The process is done through incubating the DMPE-PEG with the EVs in a $1: 1$ ratio at $40^{\circ} \mathrm{C}$ for two hours.

\section{Components of the Prime Editor}

The prime editor has two components: the catalytically impaired Cas9 endonuclease fused with an RT and a pegRNA. The Cas9 nickase H840A is attached to a Moloney murine leukemia virus (M-MLV) RT that allows it to nick one strand of the DNA. The RT domain then generates complementary DNA by copying the pegRNA to reinstate a segment of the nicked DNA strand [27]. Anzalone et al. [16] recommend starting the RT template at 10-16 nucleotides (nt) and testing shorter and longer templates during pegRNA optimization. The pegRNA encodes the desired sequence change that will correct the mutation and contains the sequence complementary to the target sites that directs the Cas 9 to its target sequence. The 5 ' of the pegRNA strand binds to the primer binding site (PBS) region on the DNA, exposing the noncomplementary strand. According to Anzalone et al., the PBS length should start at about 13 nucleotides (nt) and then different PBS lengths should also be tested. [16].

The prime editor will then be loaded into the MSCEs via the creation of liposome/exosome hybrid nanoparticles that are able to load large nucleic acids such as the prime editor. In a protocol described by Lin, Yao et al. [36], for encapsulating CRISPR-Cas9 in hybrid exosome/liposome nanoparticles, it can be theorized that it can also be used for prime editing. The liposomes, prime editor and the exosomes are incubated together for 12 hours at $37^{\circ} \mathrm{C}$ [36]. This process causes the exosomes to fuse with the liposomes and encapsulates the prime editor within the nanoparticles.

\section{Conducting In Vivo and In Vitro Studies}

In vivo studies will be conducted using mice models and the MSCEs will be delivered through intraperitoneal injection to administer the MSCEs to the mice lungs [34]. In vitro studies using human airway epithelial (hAE) organoids will be used to model the epithelial cells of the lungs of CF patients [35]. The hAE cells can be acquired from external sources such as excess surgical pathology or autopsy specimens from $\mathrm{CF}$ patients that already have the F508 mutation [35]. The MSCE encapsulated prime editor will enter the organoid cells by being introduced to the in vitro organoid environment.
Measuring Success with the Recombinant Factor VIIa (rFVII)

Our efforts to measure the efficacy of our proposal deduces to expressing the recombinant factor VIIa (rFVII), fluorescent dye and confocal microscopy. Through efforts exemplified by Peng et al. [28] with Chinese Hamster Ovary Cells (CHO), our principles lie in the expression of the recombinant rFVII protein as a proof of concept. We will be labelling MSCEs expressing the rFVII protein with a fluorescent dye (green fluorescent proteins (GFP) and then utilize confocal microscopy. We can then distinguish between positive cells (with the rFVII encoding gene).

The rFVII protein is a homeostatic substance that was first designed to treat bleeding in hemophilia A and B patients with factor VIII or IX inhibitors [29]. More recently, in CF research, this protein has been used to treat massive hemoptysis in CF patients. The mention of the rFVII protein serves the purpose of representing how the GFP protein will work. The work on Chinese Hamster Ovary Cells and cystic fibrosis by Peng et al. [28] used the $\mathrm{rFVII}$ protein as a baseline marker of the efficiency of the treatment, along with the GFP protein. Adherent cells were incubated with FVII antibody, coupled with a secondary antibody with a green fluorescent dye, and analyzed using confocal microscopy after being treated with Triton X-100 to improve membrane permeability. The two different components are stained. The nuclei are stained with DAPI (blue colour), and the rFVII in cells are stained green.

During transfection efficacy research, researchers routinely utilize fluorescent proteins with different colours as measures of success. But more specifically, we will be looking at green fluorescent proteins (GFP), which can be expressed through integration. The GFP gene has high stability, minimal toxicity, and the ability to generate green light without any external cofactors or the application of equipment. Applications of the GFP protein can monitor the efficiency of a prime edited therapy.

The last step of our efficacy method involves utilizing confocal microscopy, in which we are using the GFPlabelled rFVII marker. Confocal microscopy is an optical imaging technique that has recently surpassed traditional optical microscopy techniques [30]. Confocal microscopes achieve resolutions of $180 \mathrm{~nm}$ laterally and $500 \mathrm{~nm}$ axially. In a conventional optical epi-fluorescence microscope, secondary fluorescence generated by the sample frequently passes across the stimulated volume, blurring the clarity of features in the objective focal plane. Thicker specimens (more than 2 micrometres) exacerbate the problem since most of the fine detail is lost due to the high degree of fluorescence emission [30]. Confocal microscopy improves axial (z; along the optical axis) and lateral ( $\mathrm{x}$ and $\mathrm{y}$; in the specimen plane) optical resolution and can eliminate secondary fluorescence in areas away from the focal plane from the pictures. When working with samples of prime editing, using confocal microscopy, we can ensure that we cover and measure all portions of the therapy. 


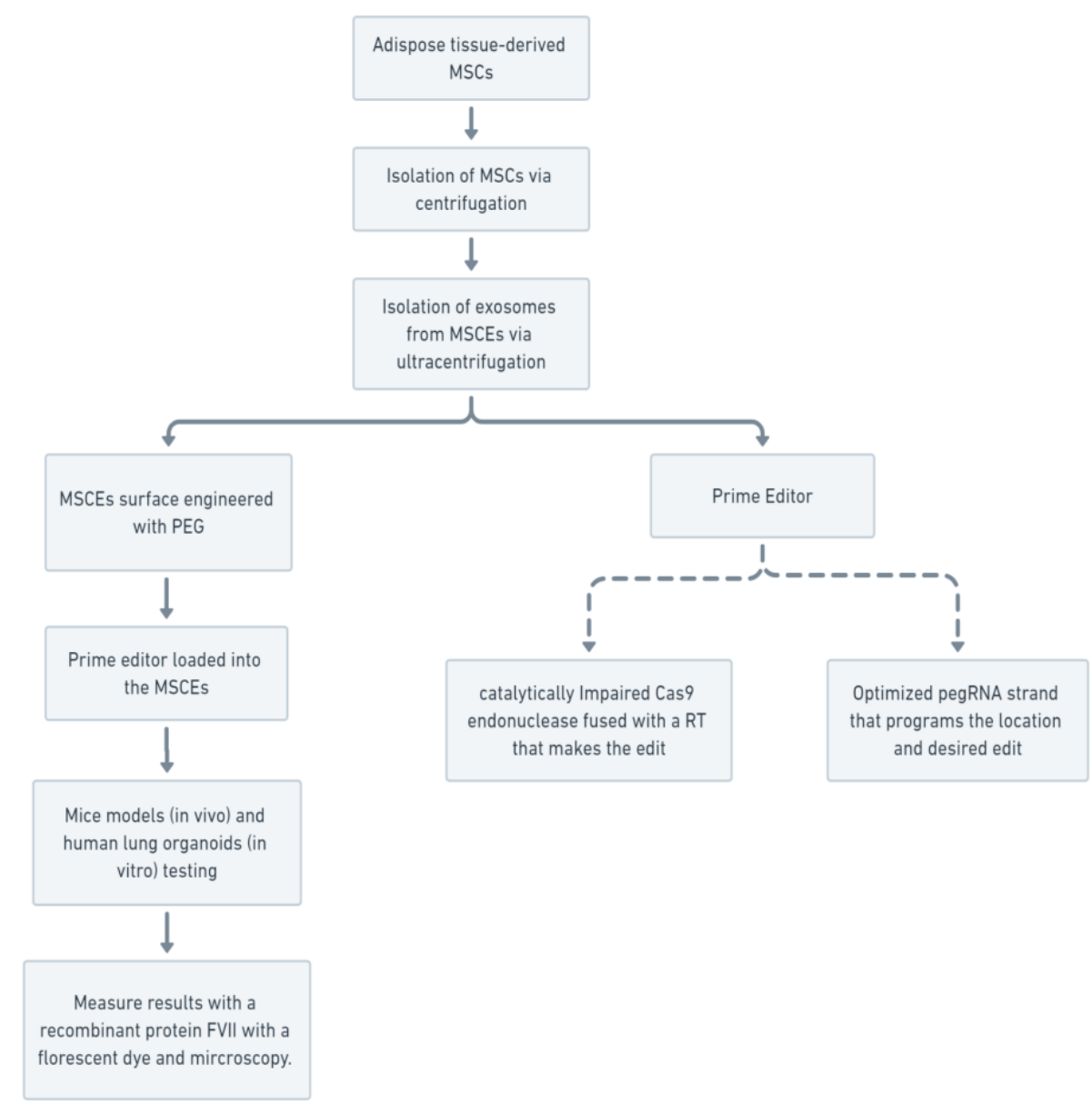

Figure 1. An overview of the experiment. The step-by-step process from harvesting the MSCs to measuring results in mice models and lung organoids. This figure was made by the authors using whimsical.com.

\section{Results}

The prime editor encased in the MSCEs will be delivered through nebulization to the lung epithelial cells. The MSCEs engineered with the PEG will allow for more MSCEs to break through the thick mucus layer and enter the lungs. The MSCEs will then transport the prime editor into the cell via endocytic uptake. Once inside the cell, the pegRNA specifies the target loci and directs the Cas9 to nick and repair the mutation. The MSCEs will also release their therapeutic RNAs that are able to reduce fibrosis and increase cell proliferation. Then using the confocal microscopy and the rFVII protein, we can detect in the mice models and the human lung organoids whether the therapy has worked, and to what degree.

\section{Discussion}

In this research protocol, the efficacy of prime editing applied in conjunction with mesenchymal stem cell-derived exosomes in the treatment of CF is tested on in vitro human lung organoids, as well as in vivo mice models. Human lung organoids are cultured to model the in vitro physiology of a human lung. Mice will be used for the in vivo animal model of the disease. After administering the prime editing and MSCE treatment, the efficacy of the treatment will be measured through dyeing MSCEs that express the rFVII protein with green fluorescent proteins (GFP). These lung organoids and euthanized mice models will be examined through confocal microscopy to eliminate secondary fluorescence, a factor that distracts from the GFP stain [30]. The role of GFP dye and microscopy is to detect the extent to which CFTR protein is functioning normally after treatment is delivered.

The degree of success of the prime editing and MSCEs treatment will be evaluated through qualitative and quantitative metrics of success. A study has reported that restoring $30 \%$ of CFTR proper gene expression in vivo translates to at least a partial clinical benefit for human $\mathrm{CF}$ patients [31]. If such an impact is detected, this measurement potentially supports the idea that this treatment approach can offer partial clinical benefits for human patients. The measurement data would provide evidence that prime editing and MSCEs produce a positive therapeutic impact on CF models. 
UNDERGRADUATE RESEARCH IN NATURAL AND CLINICAL SCIENCE AND TECHNOLOGY (URNCST) JOURNAL Read more URNCST Journal articles and submit your own today at: https://www.urnest.com

A limitation to this research protocol and clinical scalability is the high requirement of MSCEs compared to the low output of ultracentrifugation of the MSCs. The low yield of ultracentrifugation makes it hard to acquire the exosomes without compromising their integrity and functionality. The labour-intensive process of harvesting the MSCEs makes it more expensive and harder to scale. Alternatives however do exist. For instance, one could implement various sedimentation methods. As of now, sedimentation methods use solutions of lower specific gravity and there exist two methods: the pipette method and the hydrometer method. However, this alternative needs to be implemented strategically since its applicability is variable to the kind of sample one uses.

\section{Conclusion}

The proposed research protocol aims to develop a new way to treat cystic fibrosis using prime editing and MSCEs. Using permanent gene editing and regenerative medicine, prime editing and MSCEs can correct different CFTR mutations and regenerate existing damage from the disease. This approach differs from current approaches to treatment in that prime editing and MSCEs in conjunction can achieve a regenerative effect compared to the focus on the mitigation of symptoms. Treatments like CFTR modulators can only provide temporary relief and could potentially cause adverse reactions [10,12]. Further research would be necessary to determine whether one or more doses would be needed to achieve the desired effect. Prime editing has the potential to become a new way to edit the genome without double-strand breaks or donor DNA. There is no cure for CF; the average life expectancy of a patient with $\mathrm{CF}$ is around 44 years old [32]. If results are as expected, prime editing and MSCEs could bring a safe, viable option to treating $\mathrm{CF}$ and other genetic diseases.

\section{List of Abbreviations Used}

Cas9: CRISPR associated protein 9

CF: cystic fibrosis

CFTR: cystic fibrosis transmembrane conductance regulator

CHO: Chinese hamster ovaries

CRISPR: clustered regularly interspaced short palindromic sequences

DMEM: Dulbecco's modified Eagle's medium

DMPE-PEG:1,2-dimyristoyl-sn-glycero-3-

phosphoethanolamine polyethylene glycol

DNA: deoxyribonucleic acid

DSB: double-strand break

GFP: green fluorescent protein

hAE: human airway epithelial

HDR: homology-directed repair

M-MLV: Moloney murine leukaemia virus

mRNA: messenger ribonucleic acid

MSC: mesenchymal stem cells

MSCE: mesenchymal stem cell-derived exosomes

Akene et al. | URNCST Journal (2022): Volume 6, Issue 2

DOI Link: https://doi.org/10.26685/urnest.290
NHEJ: non-homologous end-joining

$\mathrm{Nt}$ : nucleotide(s)

OTE: off-target effects

PBS: phosphate-buffered saline

PBS: primer binding site

PE: prime editor

PEG: polyethylene glycol

pegRNA: prime editing guide ribonucleic acid

rFVII: recombinant factor VII

RNA: ribonucleic acid

RT: reverse transcriptase

SVT: stromal vascular fraction

USD: United States dollar

\section{Conflicts of Interest}

The author(s) declare that they have no conflict of interests.

\section{Ethics Approval and/or Participant Consent}

As this is a research proposal, it did not require ethics approval or participant consent as no humans, animals, or tissues were used in this process. If this were to be carried out, we would collect patient consent and confidentiality during the process of collecting all human-derived materials. In addition, all mice will be cared for in accordance with the ethical standards in the Canadian Council for Animal Care.

\section{Authors' Contributions}

EA: made substantial contributions to the design of the study, the collection of data as well as interpretation and analysis of the data, revised the manuscript critically, and gave final approval of the version to be published.

AP: made substantial contributions to the design of the study, the collection of data as well as interpretation and analysis of the data, revised the manuscript critically, and gave final approval of the version to be published.

JS: made substantial contributions to the design of the study, the collection of data as well as interpretation and analysis of the data, revised the manuscript critically, and gave final approval of the version to be published.

\section{Acknowledgements}

We would like to acknowledge and thank Steven ten Holder for his mentorship and guidance, scientific expertise, and writing assistance. We would also like to acknowledge Maya Chandraskaran who helped us write the original abstract. Finally, we would like to thank the IgNITE Medical Case Competition for allowing us to create this idea and engage in scientific research and writing.

\section{Funding}

This study was not funded. 
UNDERGRADUATE RESEARCH IN NATURAL AND CLINICAL SCIENCE AND TECHNOLOGY (URNCST) JOURNAL Read more URNCST Journal articles and submit your own today at: https://www.urncst.com

\section{References}

[1] Davies JC, Alton EWFW, Bush A. Cystic fibrosis. British Medical Journal. 2007;335(7632):1255-9. https://doi.org/10.1136/bmj.39391.713229.AD

[2] Boat TF, Cheng PW. Epithelial cell dysfunction in cystic fibrosis: Implications for airways disease. Acta Paediatrica. 1989;78:25-30. https://doi.org/10.1111/ apa.1989.78.s363.25

[3] Cystic Fibrosis [Internet]. Johns Hopkins medicine. [cited 2021 May 16]. Available from: https://www.hopkinsmedicine.org/health/conditionsand-diseases/cystic-fibrosis

[4] About Cystic Fibrosis [Internet]. CF Foundation. [cited 2021 May 16] Available from:

https://www.cff.org/What-is-CF/About-CysticFibrosis/Cystic fibrosis is a progressive,CFTR protein to become dysfunctional

[5] Marangi M, Pistritto G. Innovative therapeutic strategies for cystic fibrosis: Moving forward to CRISPR technique. Frontiers in Pharmacology. 2018;9. https://doi.org/10.3389/fphar.2018.00396

[6] The Cystic Fibrosis Center at Stanford. The basics of CF [Internet]. The Cystic Fibrosis Center at Stanford. [cited 2021 May 16] Available from: https://med.stanford.edu/cfcenter/education/english/Ba sicsOfCF.html

[7] Lopes-Pacheco M. CFTR modulators: The changing face of cystic fibrosis in the era of precision medicine. Frontiers in Pharmacology. 2020;10. https://doi.org/10.3389/fphar.2019.01662

[8] Habib A-RR, Kajbafzadeh M, Desai S, Yang CL, Skolnik K, Quon BS. A systematic review of the clinical efficacy and safety of CFTR modulators in cystic fibrosis. Scientific Reports. 2019;9(1). https://doi.org/10.1038/s41598-019-43652-2

[9] Editorial Team August 2, 2019. What are CFTR modulators for cystic fibrosis? [Internet]. Cystic. [cited 2021 May 16] Available from: https://cysticfibrosis.com/treatment/cftr-modulators

[10] Jennings MT, Dezube R, Paranjape S, West NE, Hong $\mathrm{G}$, Braun A, et al. An observational study of outcomes and tolerances in patients with cystic fibrosis initiated on lumacaftor/ivacaftor. Annals of the American Thoracic Society. 2017;14(11):1662-6. https://doi.org/10.1513/AnnalsATS.201701-0580C

[11] How much is too much? [Internet]. CF how much is too much. [cited 2021 May 30] Available from: https://www.primetherapeutics.com/en/news/primeinsights/2019insights/Story Cystic Fibrosis Treatments.html

[12] Pettit RS, Fellner C. CFTR modulators for the treatment of cystic fibrosis. Pharmacy and Therapeutics. 2014. Available from: https://www.ncbi.nlm.nih.gov/pmc/articles/PMC41035 77/\#b42-ptj3907500

Akene et al. | URNCST Journal (2022): Volume 6, Issue 2 DOI Link: https://doi.org/10.26685/urncst.290
[13] Wang H, Russa ML, Qi LS. CRISPR/Cas9 in genome editing and beyond. Annual Review of Biochemistry. 2016;85(1):227-64. https://doi.org/10.1146/annurevbiochem-060815-014607

[14] Uddin F, Rudin CM, Sen T. CRISPR gene therapy: Applications, limitations, and implications for the future. Frontiers in Oncology. 2020;10. https://doi.org/ 10.3389/fonc. 2020.01387

[15] Hu Z, Yu L, Zhu D, Ding W, Wang X, Zhang C, et al. Disruption of HPV16-E7 by CRISPR/Cas system induces apoptosis and growth inhibition in HPV16 positive human cervical cancer cells. BioMed Research International. 2014;2014:1-9. https://doi.org/ $\underline{10.1155 / 2014 / 612823}$

[16] Anzalone AV, Randolph PB, Davis JR, Sousa AA, Koblan LW, Levy JM, et al. Search-and-replace genome editing without double-strand breaks or donor DNA. Nature. 2019;576(7785):149-57. https://doi.org/ 10.1038/s41586-019-1711-4

[17] Rani S, Ryan AE, Griffin MD, Ritter T. Mesenchymal stem cell-derived extracellular vesicles: Toward cellfree therapeutic applications. Molecular Therapy. 2015;23(5):812-23. https://doi.org/10.1038/mt.2015.44

[18] Hass R, Kasper C, Böhm S, Jacobs R. Different populations and sources of human mesenchymal stem cells (MSC): A comparison of adult and neonatal tissuederived MSC. Cell Communication and Signaling. 2011;9(1). https://doi-org/10.1186/1478-811X-9-12

[19] Fraser JK, Wulur I, Alfonso Z, Hedrick MH. Fat tissue: An underappreciated source of stem cells for biotechnology. Trends in Biotechnology. 2006;24(4): 150-4. https://doi.org/10.1016/j.tibtech.2006.01.010

[20] Keshtkar S, Azarpira N, Ghahremani MH. Mesenchymal stem cell-derived extracellular vesicles: Novel frontiers in regenerative medicine. Stem Cell Research \& Therapy. 2018;9(1). https://doi.org/ 10.1186/s13287-018-0791-7

[21] Tieu A, Lalu MM, Slobodian M, Gnyra C, Fergusson DA, Montroy J, et al. An analysis of mesenchymal stem cell-derived extracellular vesicles for preclinical use. American Chemical Society Nanoscience. 2020;14(8):9728-43. https://doi.org/10.1021/acsnano.0c01363

[22] Bunnell B, Flaat M, Gagliardi C, Patel B, Ripoll C. Adipose-derived stem cells: Isolation, expansion and differentiation. Methods. 2008;45(2):115-20. https://doi.org/10.1016/j.ymeth.2008.03.006

[23] Zhu M, Heydarkhan-Hagvall S, Hedrick M, Benhaim P, Zuk P. Manual isolation of adipose-derived stem cells from human lipoaspirates. Journal of Visualized Experiments. 2013;(79). https://.doi.org/10.3791/50585

[24]Zuk PA, Zhu M, Mizuno H, Huang J, Futrell JW, Katz AJ, et al. Multilineage cells from human adipose tissue: Implications for cell-based therapies. Tissue Engineering. 2001;7(2):211-28. https://doi.org/ $\underline{10.1089 / 107632701300062859}$ 
UNDERGRADUATE RESEARCH IN NATURAL AND CLINICAL SCIENCE AND TECHNOLOGY (URNCST) JOURNAL

Read more URNCST Journal articles and submit your own today at: https://www.urncst.com

[25] Nikfarjam S, Rezaie J, Zolbanin NM, Jafari R. Mesenchymal stem cell derived-exosomes: A modern approach in translational medicine. Journal of Translational Medicine. 2020;18(1). https://doi.org/ $10.1186 / \mathrm{s} 12967-020-02622-3$

[26] Doyle L, Wang M. Overview of extracellular vesicles, their origin, composition, purpose, and methods for exosome isolation and analysis. Cells. 2019;8(7):727. https://doi.org/10.3390/cells8070727

[27] Matsoukas IG. Prime editing: Genome editing for rare genetic diseases without double-strand breaks or donor DNA. Frontiers in Genetics. 2020;11. https://doi.org/10.3389/fgene.2020.00528

[28] Peng L, Xiong W, Cai Y, Chen Y, He Y, Yang J, et al. A simple, rapid method for evaluation of transfection efficiency based on fluorescent dye. Bioengineered. 2016;8(3):225-31. https://doi.org/10.1080/21655979 .2016 .1222995

[29] Lau EM, Yozghatlian V, Kosky C, Moriarty C, Dentice $\mathrm{R}$, Waugh R, et al. Recombinant activated factor VII for massive hemoptysis in patients with cystic fibrosis. Chest. 2009;136(1):277-81. https://doi.org/ 10.1378/chest.08-2948

[30] Introduction to confocal microscopy [Internet]. Confocal Microscopy - Introduction Olympus LS. [cited 2021 May 31]. Available from: https://www.olympus-lifescience.com/en/microscoperesource/primer/techniques/confocal/confocalintro/
[31] Maiuri L, De Stefano D, Raia V, Kroemer G. The holy grail of cystic fibrosis research: Pharmacological repair of the F508del-CFTR mutation. Annals of Translation Medicine. 2015;3(Suppl 1):S24.

https://doi.org/10.3978/j.issn $.2305-5839.2015 .02 .32$

[32] Editorial Team July 30 2019. What's the life expectancy for someone with cystic fibrosis? [Internet]. Cystic. [2021 May 16]. Available from: https://cystic-fibrosis.com/life-expectancy

[33] Kooijmans S, Fliervoet L, Meel RVD, Fens M, Heijnen $\mathrm{H}$, Henegouwen PVBE, et al. PEGylated and targeted extracellular vesicles display enhanced cell specificity and circulation time. Journal of Controlled Release. 2016;224:77-85. https://doi.org/10.1016/j.jconrel.2016 .01 .009

[34] Behringer R, Gertsenstein M, Nagy KV, Nagy A. Administration of gonadotropins for superovulation in mice. Cold Spring Harbor Protocols. 2018;2018(1). https://doi.org/10.1101/pdb.prot092403

[35] Randell SH, Fulcher ML, O’Neal W, Olsen JC. Primary epithelial cell models for cystic fibrosis research. Methods in Molecular Biology Cystic Fibrosis. 2011;285-310. https://doi.org/10.1007/978-161779-120-8 18

[36] Lin Y, Wu J, Gu W, Huang Y, Tong Z, Huang L, et al. Exosome-liposome hybrid nanoparticles deliver CRISPR/Cas9 system in MSCs. Advanced Science. 2018; 5(4):1700611. https://doi.org/10.1002/advs.201700611

\author{
Article Information \\ Managing Editor: Jeremy Y. Ng \\ Peer Reviewers: Kate Jiang, Sonya Kouthouridis \\ Article Dates: Received Jun 01 21; Accepted Oct 29 21; Published Feb 0422
}

\title{
Citation
}

Please cite this article as follows:

Akene E, Petrovic A, Song J. Using prime editing and mesenchymal stem cell-derived exosomes to treat cystic fibrosis: A research protocol. URNCST Journal. 2022 Feb 04: 6(2). https://urncst.com/index.php/urncst/article/view/290 DOI Link: https://doi.org/10.26685/urncst.290

\section{Copyright}

(C) Erica Akene, Anastasija Petrovic, Jessica Song. (2022). Published first in the Undergraduate Research in Natural and Clinical Science and Technology (URNCST) Journal. This is an open access article distributed under the terms of the Creative Commons Attribution License (https://creativecommons.org/licenses/by/4.0/), which permits unrestricted use, distribution, and reproduction in any medium, provided the original work, first published in the Undergraduate Research in Natural and Clinical Science and Technology (URNCST) Journal, is properly cited. The complete bibliographic information, a link to the original publication on http://www.urncst.com, as well as this copyright and license information must be included. 


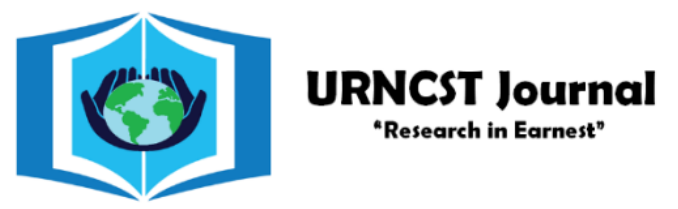

\section{Funded by the Government of Canada}

\section{Canadà̀}

Do you research in earnest? Submit your next undergraduate research article to the URNCST Journal!

| Open Access | Peer-Reviewed | Rapid Turnaround Time | International | | Broad and Multidisciplinary | Indexed | Innovative | Social Media Promoted |

Pre-submission inquiries? Send us an email at info@urncst.com | Facebook, Twitter and LinkedIn: @URNCST Submit YOUR manuscript today at https://www.urncst.com! 